\title{
Commentary Can the stroma provide the clue to the cellular basis for mammographic density?
}

\author{
Ruth Warren ${ }^{1}$ and Sunil R Lakhani ${ }^{2}$ \\ ${ }^{1}$ Department of Radiology, Addenbrooke's Hospital, Cambridge and University of Cambridge, UK \\ ${ }^{2}$ The Breakthrough Toby Robins Breast Cancer Research Centre, Institute of Cancer Research and The Royal Marsden Hospital, London, UK \\ Corresponding author: Ruth Warren (e-mail: rmlw2@cam.ac.uk)
}

Published: 23 July 2003

Breast Cancer Res 2003, 5:225-227 (DOI 10.1186/bcr642)

(c) 2003 BioMed Central Ltd (Print ISSN 1465-5411; Online ISSN 1465-542X)

See related Research article: http://breast-cancer-research.com/content/5/5/R129

\begin{abstract}
Mammographic density is recognised as a useful phenotypic biomarker of breast cancer risk. Deeper understanding is needed of the cellular basis, but evidence is limited because of difficulty in designing studies to validate hypotheses. The ductal epithelial components do not adequately explain the physical and dynamic features observed. The stroma is thought to interact with ductal structures in cancer initiation. Stromal tissues might account for the mammographic features, and this interplay can be hypothesised to relate risk to density. In a paper in this issue of Breast Cancer Research, Alowami has shown a relationship between density and stromal proteins, which might provide useful insight into mammographic density.
\end{abstract}

Keywords: breast cancer risk, mammographic density, stromal proteins

\section{Introduction}

For many years it has been recognised that radiographic density of the breast tissues on the mammogram is associated with the risk of developing cancer, and that women with the densest pattern have a 4-6 times relative risk of breast cancer compared with women with the most lucent pattern. Recently the huge potential of this observation for detecting and monitoring risk has been recognised, and is enabled by the implementation of routine mammographic screening of the normal population and those at increased risk in whom screening can start from as young as 30 years. The cellular basis for the differences between individuals has never been fully explained. There has been no firm evidence for the quasi-pathological descriptions used. The paper by Alowami and colleagues in this issue provides an interesting clue, supported by data, for the stroma and its proteins as determinant factors in this radiographic density on the mammogram [1].

\section{Breast density as a biomarker of risk}

Wolfe first described a means of categorising the appearances of breast tissue on the mammogram and showed that the densest patterns were associated with an increased risk of developing breast cancer when compared with mammograms showing chiefly fatty appearances [2]. For years this was debated and doubted in the literature, but in the late 1990s many observers confirmed this relationship conclusively, and the risk-density relationships were explored in high-quality epidemiological studies. This literature has recently been comprehensively reviewed by Heine [3,4] and appraised by Byrne [5] for the way in which it reveals an understanding of breast cancer.

One of the commonest reasons for having an increased risk of breast cancer is family history, and a recent study of twins has demonstrated that about $60 \%$ of the density can be accounted for by heritable factors, the remaining proportion lying in lifestyle and mutable factors [6]. Density has been shown to be associated with the lifestyle risk factors known for breast cancer such as late age at first birth, and nulliparity [7]. It is also increased in women on hormone replacement therapy (HRT) [7] and decreased in women on tamoxifen [8]. It has been associated with dietary constituents believed to be associated 
with breast cancer causation [9]. The two major risk factors for breast cancer that are inversely related to breast density are raised body mass index [10] and age [11], both of which give rise to more fatty breasts.

When the nature of the tumours associated with higher risk patterns on mammography is examined, they are more likely to be grade 3 tumours, with nodes positive, of large size and with ductal carcinoma in situ; this is independent of the masking effect of dense glandular tissue on mammographic diagnosis $[12,13]$. Change in density occurs with time, diminishing with advancing age, but increasing on HRT. This change can be measured, and might be a method of monitoring the effects of intervention on individual risk [14] - as for example with chemoprevention. Does change in density actually denote change in risk? This link has not yet been made in the published evidence available.

\section{Knowledge of the cellular basis for mammographic density}

What, then, is known of the cellular basis for these observations? The literature on this is much smaller, and the question is curiously difficult to answer. There are limitations on all available methods, which introduce different biases. Some workers have looked at autopsy material and have been able to examine the relationship between dense patterns and evidence of, for example, proliferative fibrocystic change [15]. In this situation, although detailed and accurate pathological examination can be performed, the mammography is suboptimal because it is on a postmortem mastectomy specimen. When the problem is tackled with a case-control study, the controls do not have their tissue examined, whereas examination of the cases might be biased owing to the reason for obtaining biopsy tissue. In contrast, the mammography is from live women with standard techniques [16]. The tissues are rarely 'normal' because the two main types of specimens examined are benign tissues from patients with cancer or prophylactic mastectomies in high-risk women. This shortfall might be resolved by using biopsy material from the control population, but this raises both ethical difficulties and technical problems in relating the biopsy site to the mammographic feature.

\section{The physical basis for tissue appearances on mammography}

Most studies recognise that the radiographically lucent tissue is fat, and that the water-dense material is due to epithelial and stromal elements. The physical methods of measurement essentially divide the tissues into fat and 'glandular elements', namely tissues with the same density as water [17]. Information gained from ultrasound and magnetic resonance imaging [18] might be looking at the same features, but using different physical principles. Their that cancers 'arise' commonly in fatty tissue, and so there is epithelial tissue present that is not seen on the mammogram, but from which the cancer arises. An early (1990) publication from Nottingham describing a case-control study concluded that the density was related to fibrous and adipose tissues in the interlobular stroma and bore no relationship to the epithelial parenchymal content [19].

\section{Relationship of density to epithelial pathologies}

Nevertheless, many of the papers since then that explore the issue have concentrated on the relationship to epithelial proliferations - hyperplasia, atypical hyperplasia, carcinoma in situ and fibrocystic change, echoing the original name given by Wolfe to the densest pattern, 'DY', hinting at 'dysplasia' as the origin [2]. Several authors $[16,20,21]$ have explored these relationships and have shown a weak link between these epithelial abnormalities and dense patterns. Despite this, it has been increasingly accepted that epithelial proliferation is unlikely to account for the increased mammographic density.

\section{The stroma as a dynamic component in breast carcinogenesis}

There is recent evidence that the stroma is not inert but that there might be an interplay between the breast epithelial and stromal compartments, which have an effect on the growth and progression of a breast tumour. Evidence of loss of heterozygosity $(\mathrm{LOH})$ has been demonstrated in both epithelial and stromal compartments by Kurose and colleagues [22] and others, suggesting that stromal changes might have a crucial role in breast carcinogenesis. Finding of $\mathrm{LOH}$ in the two compartments does not prove a causality of effect of one component over the other; nonetheless, the data are intriguing. They fit with the non-reductionist view that breast cancer is more than just an abnormality of epithelial cells and that the stroma, inflammatory cells and endothelial proliferation are an integral part of the tumour. Guo and colleagues [23] found that increased tissue cellularity, greater amounts of collagen, increased insulin-like growth factor-1 and tissue metalloproteinase- 3 were found in tissue from dense breasts in women under 50 years of age, and proposed a relationship by which increased risk might be mediated.

\section{Density changes with time}

A feature of the density problem that must be taken into account in any hypothesis of the underlying cellular process is the relatively rapid changes that can occur in breast density - for example, there is evidence of change within the menstrual cycle [24]. Relatively rapid changes due to hormones have also been shown [25]. Is this to be accounted for by water retention within existing cells, or changes in the number of cells? Further, the relationship holds good at all ages, so findings must apply before and after the menopause. 


\section{Evidence from stromal proteins}

Watson's group have previously examined the stromal proteins lumican and decorin in breast tumours and normal tissues and have shown that they are inversely regulated in association with breast carcinogenesis [26]. This present contribution explores these proteins and shows them to be related to dense patterns. The authors showed higher collagen density and extent of fibrosis but found no significant difference in the density of ductal and lobular units (epithelial component). This small project starts to elucidate a hypothesis by which density might relate to risk through an interplay between the stromal and epithelial structures. This could provide a means by which change in density might influence factors that have an effect on the initiation and progression of a breast tumour.

\section{Conclusion}

Further work in this area might be productive in giving a better understanding of this relationship between density and risk. More understanding is needed if density measures are to be used to estimate individual risk and to monitor change in a meaningful way. The expression of significant cellular markers, stromal proteins, genetic changes ( $\mathrm{LOH}$ and comparative genomic hybridisation) or expression profiles could be assessed on biopsy specimens in association with the mammograms so that the risk-density relationship can be more fully understood. This might be an ethically justifiable tool for research or in the risk assessment of high-risk women.

\section{Competing interests}

None declared.

\section{References}

1. Alowami S, Troup S, Al-Haddad S, Kirkpatrick I, Watson P: Mammographic density is related to stroma and stromal proteoglycan expression. Breast Cancer Res 2003, 5:R129R135.

2. Wolfe JN: Risk for breast cancer development determined by mammographic parenchymal pattern. Cancer 1976, 37:24862492.

3. Heine JJ, Malhotra P: Mammographic tissue, breast cancer risk, serial image analysis, and digital mammography. Part 2. Serial breast tissue change and related temporal influences. Acad Radiol 2002, 9:317-335.

4. Heine JJ, Malhotra P: Mammographic tissue, breast cancer risk, serial image analysis, and digital mammography. Part 1. Tissue and related risk factors. Acad Radiol 2002, 9:298316.

5. Byrne C: Studying mammographic density: implications for understanding breast cancer [editorial; comment]. J Natl Cancer Inst 1997, 89:531-533.

6. Boyd NF, Dite GS, Stone J, Gunasekara A, English DR, McCredie MR, Giles GG, Tritchler D, Chiarelli A, Yaffe MJ, Hopper JL: Heritability of mammographic density, a risk factor for breast cancer. N Engl J Med 2002, 347:886-894.

7. Vachon CM, Kuni CC, Anderson K, Anderson VE, Sellers TA: Association of mammographically defined percent breast density with epidemiologic risk factors for breast cancer (United States). Cancer Causes Contro/ 2000, 11:653-662.

8. Atkinson C, Warren R, Bingham SA, Day NE: Mammographic patterns as a predictive biomarker of breast cancer risk: effect of tamoxifen. Cancer Epidemiol Biomarkers Prev 1999, 8: 863-866.
9. Sala E, Warren R, Duffy S, Welch A, Luben R, Day N: High risk mammographic parenchymal patterns and diet: a casecontrol study. $\mathrm{Br} J$ Cancer 2000, 83:121-126.

10. Sala E, Warren R, McCann J, Duffy S, Luben R, Day N: High-risk mammographic parenchymal patterns and anthropometric measures: a case-control study. Br J Cancer 1999, 81:12571261

11. van Gils $\mathrm{CH}$, Otten JD, Verbeek AL, Hendriks JH: Short communication: breast parenchymal patterns and their changes with age. Br J Radiol 1995, 68:1133-1135.

12. Sala E, Solomon L, Warren R, McCann J, Duffy S, Luben R, Day $\mathrm{N}$ : Size, node status, and grade of breast tumours: association with mammographic parenchymal patterns. Eur Radiol 2000, 10:157-161.

13. Sala E, Warren R, McCann J, Duffy S, Luben R, Day N: Mammographic parenchymal patterns and breast cancer natural history - a case-control study. Acta Oncol 2001, 40:461-465.

14. Boyd NF, Martin LJ, Stone J, Greenberg C, Minkin S, Yaffe MJ: Mammographic densities as a marker of human breast cancer risk and their use in chemoprevention. Curr Oncol Rep 2001, 3:314-321.

15. Bartow S, Pathak D, Mettler F: Radiographic microcalcification and parenchymal pattern as indicators of histologic 'high-risk' benign breast disease. Cancer 1990, 66:1721-1725.

16. Friedenreich $\mathrm{C}$, Bryant $\mathrm{H}$, Alexander F, Hugh J, Danylik J, Page D: Risk factors for benign breast biopsies: a nested case-control study in the Alberta breast screening programme. Cancer Detect Prev 2001, 25:280-291.

17. Kaufhold J, Thomas J, Eberhard J, Galbo C, Trotter D: A calibration approach to glandular tissue composition estimation in digital mammography. Med Phys 2002, 29:1867-1880.

18. Lee N, Rusinek H, Weinreb J, Chandra R, Toth H, Singer C, Newstead G: Fatty and fibroglandular tissue volume in the breasts of women 20-83 years old: comparison of X-ray mammography and computer-assisted MR imaging. $\mathrm{Am} J$ Roentgenol 1997, 168:501-506.

19. Arthur JE, Ellis IO, Flowers C, Roebuck E, Elston CW, Blamey RW: The relationship of 'high risk' mammographic patterns to histological risk factors for development of cancer in the human breast. Br J Radiol 1990, 63:845-849.

20. Boyd NF, Jensen H, Cooke G, Lee Han H, Lockwood G, Miller A: Mammographic densities and the prevalence and incidence of histological types of benign breast disease. Eur J Cancer Prev 2000, 9:15-24.

21. Byrne C, Schairer C, Brinton L, Wolfe J, Parekh N, Salane M, Carter C, Hoover R: Effects of mammographic density and benign breast disease on breast cancer risk. Cancer Causes Control 2001, 12:103-110.

22. Kurose K, Hoshaw-Woodward S, Adeyinka A, Lemeshow S, Watson P, Eng C: Genetic model of multi-step breast carcinogenesis involving the epithelium and stroma: clues to tumour-microenvironment interactions. Hum Mol Genet 2001, 10:1907-1913.

23. Guo Y, Martin L, Hanna W, Banerjee D, Miller N, Fishell E, Khokha R, Boyd NF: Growth factors and stromal matrix proteins associated with mammographic densities. Cancer Epidemiol Biomarkers Prev 2001, 10:243-248.

24. White $E$, Velentgas $P$, Mandelson $M$, Lehman C, Elmore J, Porter $P$ : Variation in mammographic breast density by time in menstrual cycle among women aged 40-49 years. J Natl Cancer Inst 1998, 90:906-910.

25. Colacurci N, Fornaro F, De Francisco P, Mele D, Palermo M, del Ve W: Effects of a short-term suspension of hormone replacement therapy on mammographic density. Fertil Steril 2001, 76:451-455.

26. Leygue E, Snell L, Dotzlaw H, Troup S, Hiller-Hitchcock T, Murphy L, Roughley PJ, Watson PH: Lumican and decorin are differently expressed in human breast carcinoma. J Pathol 2000, 192:313-320.

\section{Correspondence}

Ruth Warren, Cambridge Breast Unit, Addenbrooke's Hospital, Cambridge CB2 2QQ, UK. Tel: +44 1223 217627; fax: +44 1223 217886; e-mail: rmlw2@cam.ac.uk 